Author: AKHMETOV Rasul Tukhbatullovich, Ph.D. in Engineering, Professor, Deputy Head of the Department of «Oil and Gas Field Exploration and Development», Oktyabrsky Branch of Ufa State Petroleum Technological University, Devonskaya St., 54a, Oktyabrsky, Republic of Bashkortostan, Russian Federation, 452607, +7(34767)65590, 66404, vsh@of.ugntu.ru;

Author: ANDREEV Anton Vadimovich, Ph.D. in Engineering, Associate Professor at the Department of «Oil and Gas Field Exploration and Development», Oktyabrsky Branch of Ufa State Petroleum Technological University, Devonskaya St., 54a, Oktyabrsky, Republic of Bashkortostan, Russian Federation, 452607,+7(34767) 65590,66404, vsh@of.ugntu.ru;

Author: MUKHAMETSHIN Vyacheslav Vyacheslavovich, Ph.D. in Engineering, Associate Professor at the Department of «Oil and Gas-And-Oil Field Development and Operation», Ufa State Petroleum Technological University, Kosmonavtov St., 1, Ufa city, Republic of Bashkortostan, Russian Federation, 450062,+7(34767)6-55-90,6-64-04,vsh@of.ugntu.ru

\title{
RESIDUAL OIL SATURATION AND THE DISPLACEMENT FACTOR PREDICTION METHODOLOGY BASED ON GEOPHYSICAL STUDIES DATA TO EVALUATE EFFICIENCY OF NANOTECHNOLOGIES APPLICATION
}

\section{Extended Abstract:}

The displacement factor is important information when it is necessary to evaluate oil production dynamics and the prospects of development intensification and oil recovery enhancing methods, including nanotechnological methods. However, up to date there are no reliable oil-field methods to predict this parameter in situ well, under conditions of the natural reservoirs occurrence, and that causes this important parameter not to be taken into account when the impact on the bottomhole formation zone effectiveness is evaluated.

In this paper the authors propose a methodology for prediction of the displacement factor that employs field geophysics data and that makes it possible to estimate this parameter in each geological cross-section both in the section and in the deposit area.

The method is based on the use of two complex parameters characterizing the filtration properties and the productive formation hydrophilicity (hydrophobicity) degree. The both complex parameters are easily determined by the standard well logging complex data. 
At present the technologies that use solutions containing $\mathrm{SiO}_{2}$ nanoparticles are becoming more and more popular in oil production intensification and enhanced oil recovery process.

The proposed calculation method for residual oil saturation and displacement coefficient can be used to obtain the reference values of the corresponding parameters when the efficiency of oil production intensification and enhanced oil recovery methods including nanotechnological ones is evaluated.

Key words: residual oil saturation, displacement factor, wettability, nanotechnologies, technological effect.

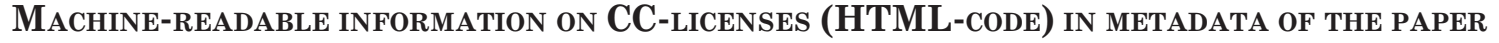

$<$ a rel="license" href="http://creativecommons.org/licenses/by/4.0/" $><$ img alt="Creative Commons License" style="borderwidth:0" src="https://i.creativecommons.org/l/by/4.0/88x31.png" $/></ \mathrm{a}><$ br $/><$ span xmlns:dct="http://purl.org/dc/ terms/" href="http://purl.org/dc/dcmitype/Text" property="dct:title" rel="dct:type" $>$ Residual oil saturation and the displacement factor prediction methodology based on geophysical studies data to evaluate efficiency of nanotechnologies application. $</$ span $>$ by $<$ a xmlns:cc="http://creativecommons.org/ns\#" href="Nanotehnologii $v$ stroitel'stve $=$

Nanotechnologies in Construction. 2017, Vol. 9, no. 5, pp. 116-133. DOI: dx.doi.org/10.15828/2075-8545-2017-9-5-116-

133. " property="cc:attributionName" rel="cc:attributionURL">Akhmetov R.T., Andreev A.V., Mukhametshin V.V. $</ a>$ is licensed under a $<$ a rel="license" href="http://creativecommons.org/licenses/by/4.0/" $>$ Creative Commons Attribution 4.0 International License $</ \mathrm{a}>$. $<$ br $/>$ Based on a work at $<$ a xmlns:det="http://purl.org/dc/terms/" href=" http://nanobuild. ru/en_EN/nanobuild-5-2017/" rel="dct:source"> http://nanobuild.ru/en_EN/nanobuild-5-2017/</a $>$. $<$ br $/>$ Permissions beyond the scope of this license may be available at $<\mathrm{a}$ xmlns:cc="http://creativecommons.org/ns\#" href="vsh@of.ugntu.ru" rel="cc:morePermissions" $>$ vsh@of.ugntu.ru $</ a>$.
}

\section{References:}

1. Gudok N.S. Izuchenie fizicheskikh svoystv poristykh sred [The study of physical properties of porous media]. Moscow. Nedra, 1970. 208 p. (In Russian).

2. Tulbovich B.I. Kollektorskie svoystva i khimiya poverkhnosti produktivnykh porod [Collector properties and surface chemistry of productive rocks]. Perm. Perm book publishing house, 1975. 194 p. (In Russian).

3. Khayredinov N.Sh., Popov A.M., Mukhametshin V.Sh. Povyshenie effektivnosti zavodneniya nizkoproduktivnykh zalezhey nefti v karbonatnykh kollektorakh [Increasing the flooding efficiency of poor-producing oil deposits in carbonate]. Oil industry, 1992. № 9. P. 18-20. (In Russian).

4. Tulbovich B.I. Petrofizicheskoe obespechenie effektivnogo izvlecheniya uglevodorodov [Petrophysical provision of effective hydrocarbon recovery]. Moscow. Nedra, 1990. $186 \mathrm{p}$. (In Russian). 
5. Tulbovich B.I. Metody izucheniya porod-kollektorov nefti i gaza [Methods of studying reservoir rocks of oil and gas]. Moscow. Nedra, 1979. 199 p. (In Russian).

6. Gimatudinov Sh.K., Borisov Yu.P., Rozenberg M.D. Spravochnoe rukovodstvo po proektirovaniyu razrabotki i ekspluatatsii neftyanykh mestorozhdeniy [Reference Guide for Designing the Development and Operation of Oil Fields]. Moscow. Nedra, 1983. 483 p. (In Russian).

7. Kadyrov R.R., Nizaev R.Kh., Yartiev A.F., Mukhametshin V.V. Ogranichenie vodopritoka $\mathrm{v}$ gorizontalnykh skvazhinakh na mestorozhdeniyakh $\mathrm{s}$ trudnoizvlekaemymi zapasami nefti [A novel water shut-off technique for horizontal wells at fields with hard-to-recover oil reserves]. Oil industry, 2017. № 5. P. 44-47. (In Russian).

8. Andreev A.V., Mukhametshin V.Sh., Kotenev Yu.A. Deposit Productivity Forecast in Carbonate Reservoirs with Hard to Recover Reserve. SOCAR Proceedings. 2016. № 3. P. 40-45.

9. Mukhametshin V.Sh., Zeigman Yu.V., Andreev A.V. Rapid assessment of deposit production capacity for determination of nanotechnologies application efficiency and necessity to stimulate their development. Nanotehnologii v stroitel'stve $=$ Nanotechnologies in Construction, 2017. Vol. 9, № 3. P. 20-34. DOI: dx.doi.org/10.15828/2075-8545-20179-3-20-34. (In Russian).

10. Surguchev M.L., Kolganov V.I., Gavura A.V. et al. Izvlechenie nefti iz karbonatnykh kollektorov [Extraction of oil from carbonate reservoirs]. Moscow. Nedra, 1987. 230 p. (In Russian).

11. Mikhailov N.N., Dzhemesyuk A.V., Kolchitskaya T.N. et al. Izuchenie ostatochnogo neftenasyshcheniya razrabatyvaemykh plastov [Study of residual oil saturation of the developed layers]. Moscow. VNIIOENG, 1990. 100 p. (In Russian).

12. Mukhametshin V.V., Andreev V.E., Dubinsky G.S. et al. The Usage of Principles of System Geological-Technological Forecasting in the Justification of the Recovery Methods. SOCAR Proceedings. 2016. № 3. P. 46-51.

13. Ter-Sarkisov R.M., Maksimov V.M., Basniev K.S. et al. Geologicheskoe i gidrotermodinamicheskoe modelirovanie mestorozhdeniy nefti i gaza [Geological and hydrothermodynamic modeling of oil and gas fields]. Izhevsk. Institute of Computer Research, 2012. 452 p. (In Russian).

14. Zeigman Yu.V., Mukhametshin V.Sh., Sergeev V.V. et al. Experimental study of viscosity properties of emulsion system with $\mathrm{SiO} 2$ nanoparticles. Nanotehnologii v stroitel'stve $=$ Nanotechnologies in Construction, 2017. Vol. 9, № 2. P. 16-38. DOI: dx.doi. org/10.15828/2075-8545-2017-9-2-16-38. (In Russian).

15. Mukhametshin V.V. O neobkhodimosti i sozdanii edinogo kompleksnogo metoda geologopromyslovogo analiza i obobshcheniya effektivnosti vozdeystviya na prizaboynuyu zonu plasta [The need for creation of a unified comprehensive method of geological and field analysis and integration of data on effective influence on the bottom-hole formation zone]. Oil industry, 2017. № 4. P. 80-84. (In Russian).

16. Mukhametshin V.V., Andreev V.E., Zeigman Yu.V. et al. Snizhenie riskov prinyatiya nizkoeffektivnykh upravlyayushhikh resheniy pri ispolzovanii kislotnykh sostavov, predotvrashchayushchikh emulsioobrazovanie [Reducing risks of low-efficiency managerial de- 
cision-making when using acidization compositions preventing emulsification]. Geology, Geophysics and Development of Oil and Gas Fields, 2017. № 5. P. 36-42. (In Russian).

17. Yakupov R.F., Mukhametshin V.Sh. Voprosy effektivnosti razrabotki nizkoproduktivnykh karbonatnykh kollektorov na primere turneyskogo yarusa Tuymazinskogo mestorozhdeniya [Problem of efficiency of low-productivity carbonate reservoir development on example of Turnaisian stage of Tuymazinskoye field]. Oil industry, 2013. № 12. P. 106110. (In Russian).

18. Zeigman Yu.V., Mukhametshin V.Sh., Khafizov A.R. et al. Osobennosti vybora sostavov zhidkostey glusheniya skvazhin v oslozhnennykh usloviyakh ekspluatatsii skvazhin [Peculiarities of selecting well-killing fluids composition for difficult conditions]. Oil industry, 2017. № 1. P. 66-69. (In Russian).

19. Mukhametshin V.Sh. Zavisimost nefteizvlecheniya ot plotnosti setki skvazhin pri razrabotke nizkoproduktivnykh karbonatnykh zalezhey [Dependence of crude-oil recovery on the well spacing density during development of low-producing carbonate deposits]. Oil industry, 1989. № 12. P. 26-29. (In Russian).

20. Akhmetov R.T., Kneller L.E. Prognoz absolyutnoy pronitsaemosti granulyarnykh kollektorov na osnove gantelnoy modeli pustotnogo prostranstva [Forecast for absolute permeability of granular reservoirs on the basis of the dumbbell simulation of the void space]. Karotazhnik, 2013. № 7 (229). P. 75-88. (In Russian).

21. Akhmetov R.T., Mukhametshin V.Sh. Koeffitsient absolyutnoy pronitsaemosti v ramkakh gantelnoy modeli [Absolute permeability factor in dumb-bell pattern]. Neftegazovoe delo, 2012. № 1. P. 341-352. (In Russian).

22. Akhmetov R.T., Mukhametshin V.V., Andreev A.V. Interpretatsiya krivykh kapillyarnogo davleniya pri smeshannoy smachivaemosti [Interpretation of capillary pressure curves in case of mixed-wettability]. Geology, Geophysics and Development of Oil and Gas Fields, 2017. № 4. P. 40-43. (In Russian).

23. Akhmetov R.T., Zeigman Yu.V., Mukhametshin V.V. et al. Prognoz pokazatelya smachivaemosti produktivnykh plastov po obemnomu soderzhaniyu ostatochnoy vody [Forecast of wettability index in productive formations by volume of residual water content]. Higher Educational Institutions News. Neft’ I Gas. 2017. № 2. P. 39-43. (In Russian).

24. Akhmetov R.T. Kolichestvennaya otsenka pronitsaemosti karbonatnykh kollektorov kashiro-podolskikh otlozheniy Arlanskogo mestorozhdeniya po dannym GIS [Quantitative estimation of permeability of carbonate reservoirs of Kashiro-Podolsk deposits of the Arlansky deposit based on GIS data]. Collection of scientific papers of BashNIPIneft. Ufa, 1995. Iss. 91. (In Russian).

25. Zlobin A.A. Vliyanie smachivaemosti porod-kollektorov na koeffitsient izvlecheniya nefti [Impact of rock-collectors wettability on oil recovery factor]. Oilfield engineering, 2013. № 9. P. 49-53. (In Russian).

26. Mikhailov A.N. Vliyanie kapillyarnykh kontsevykh effektov na pokazateli razrabotki [Influence of capillary trailing effects on development parameters]. Oil industry, 2013. № 9. P. 54-56. (In Russian). 
27. Mikhailov N.N., Semenova N.A., Sechina L.S. Vliyanie mikrostrukturnoy smachivaemosti na petrofizicheskie kharakteristiki porod-kollektorov [The influence of microstructure wetting on the petrophysical characteristics of the reservoir rocks]. Karotazhnik, 2011. № 7. P. 163-172. (In Russian).

28. Xizhnyak G.P., Amirov A.M., Mosheva A.M. et al. Vliyanie smachivaemosti na koeffitsient vytesneniya nefti [Influence of wettability on oil displacement efficiency]. Perm Journal of Petroleum and Mining Engineering, 2013. Vol. 12, № 6. P. 54-63. (In Russian).

29. Mikhailov A.N., Melekhin S.V. Teoreticheskie i eksperimentalnye issledovaniya osobennostey vytesneniya nefti vodoy iz plastov s kontrastnoy smachivaemostyu [Theoretical and experimental studies of special properties of water-oil displacement in reservoirs with contrast wettability]. Vestnik CKR Rosnedra, 2014. № 1. P. 12-18. (In Russian).

30. Mikhailov N.N., Motorova K.A., Sechina L.S. Geologicheskie faktory smachivaemosti porod-kollektorov nefti i gaza [Geological factors of wettability of reservoir rocks of oil and gas]. Business magazine Neftegaz.RU, 2016. № 3. P. 80-90. (In Russian).

31. Mikhailov N.N., Motorova K.A., Sechina L.S. Vliyanie sostava uglevodorodov na gidrofobizatsiyu karbonatnykh porod [Influence of the composition of hydrocarbons on the hydrophobization of carbonate rocks]. Abstracts of the V International Scientific Symposium «Theory and Practice of Application of Enhanced Oil Recovery Techniques», 2015. P. 29-36. (In Russian).

32. Akhmetov R.T., V.Sh. Mukhametshin, Andreev V.E. Prognoz pokazatelya smachivaemosti produktivnykh plastov po dannym promyslovoy geofiziki [Field geophysics forecast of productive reservoir wettability index]. Geology, Geophysics and Development of Oil and Gas Fields, 2016. № 2. P. 21-25. (In Russian).

33. Akhmetov R.T., Mukhametshin V.V. Vodouderzhivayushchaya sposobnost i smachivaemost produktivnykh plastov [Water-retaining capacity and wettability of productive formation]. Neftegazovoe delo, 2016. Vol. 14, № 2. P. 34-37. (In Russian).

\section{DeAr COLleagues!}

The REFERENCE TO THIS PAPER hAS THE FOLLOWING CITATION FORMAT:

Akhmetov R.T., Andreev A.V., Mukhametshin V.V. Residual oil saturation and the displacement factor prediction methodology based on geophysical studies data to evaluate efficiency of nanotechnologies application. Nanotehnologii v stroitel'stve $=$ Nanotechnologies in Construction. 2017, Vol. 9, no. 5, pp. 116133. DOI: dx.doi.org/10.15828/2075-8545-2017-9-5-116-133. (In Russian). 
Автор: АХМЕТОВ Расуль Тухбатуллович, канд. техн. наук, проф., зам. зав. каф. «Разведка и разработка нефтяных и газовых месторождений», филиал УГНТУ в городе Октябрьском; ул. Девонская, 54a, г. Октябрьский, Республика Башкортостан, Россия, 452607, vsh@of.ugntu.ru; Автор: АНДРЕЕВ Антон Вадимович, канд. техн. наук, доцент каф. «Разведка и разработка нефтяных и газовых месторождений», филиал УГНТУ в городе Октябрьском; ул. Девонская, 54а, г. Октябрьский, Республика Башкортостан, Россия, 452607, vsh@of.ugntu.ru;

Автор: МУХАМЕТШИН Вячеслав Вячеславович, канд. техн. наук, доцент каф. «Разработка и эксплуатация нефтяных и газонефтяных месторождений», Федеральное государственное бюджетное образовательное учреждение высшего образования «Уфимский государственный нефтяной технический университет»; ул. Космонавтов, 1, г. Уфа, Республика Башкортостан, Россия, 450062, vsh@of.ugntu.ru

\section{МЕТОДИКА ПРОГНОЗА ОСТАТОЧНОЙ НЕФТЕНАСЫЩЕННОСТИ И КОЭФФИЦИЕНТА ВЫТЕСНЕНИЯ ПО ДАННЫМ ГЕОФИЗИЧЕСКИХ ИССЛЕДОВАНИЙ ДЛЯ ОЦЕНКИ ЭФФЕКТИВНОСТИ ПРИМЕНЕНИЯ НАНОТЕХНОЛОГИЙ}

АННОТАЦИЯ К СТАТЬЕ (АВТОРСКОЕ РЕЗЮМЕ, РЕФЕРАТ):

Коэффициент вытеснения является важной информацией при оценке динамики добычи нефти и перспектив применения методов интенсификации разработки и повышения нефтеотдачи, в том числе с использованием нанотехнологий. Однако до настоящего времени отсутствуют надежные промысловые методы прогнозирования данного параметра непосредственно в скважине, в условиях естественного залегания продуктивных пластов, что является причиной неучета этого важного параметра при оценке эффективности воздействия на призабойную зону пласта.

В настоящей работе предлагается методика прогноза коэффициента вытеснения по данным промысловой геофизики, позволяющая оценить данный параметр в каждом пластопересечении как по разрезу, так и по площади месторождения.

Методика основана на использовании двух комплексных параметров, характеризующих фильтрационные свойства и степень гидрофильности (гидрофобности) продуктивного пласта. Оба комплексных параметра легко 
определяются по данным стандартного комплекса геофизических исследований скважин.

В настоящее время при интенсификации добычи и повышения нефтеотдачи пластов набирают популярность технологии, использующие растворы, содержащие наночастицы $\mathrm{SiO}_{2}$.

Предлагаемый способ расчета остаточной нефтенасыщенности и коэффициента вытеснения можно использовать для получения базовых значений соответствующих параметров при оценке эффективности методов интенсификации и повышения нефтеотдачи, в том числе с использованием нанотехнологий.

Ключевые слова: остаточная нефтенасыщенность, коэффициент вытеснения, смачиваемость, нанотехнологии, технологический эффект.

DOI: dx.doi.org/10.15828/2075-8545-2017-9-5-116-133

МАшИНОЧИТАЕМАЯ ИНФОРМАЦИЯ о CC-ЛИЦЕНЗИИ в МЕТАДАННЫХ СТАТЬИ (НTML-КОД):

$<$ a rel="license" href="http://creativecommons.org/licenses/by/4.0/"><img alt="Лицензия Creative Commons" style="borderwidth:0" src="https://i.creativecommons.org/l/by/4.0/88x31.png" / ></a $><$ br / $>$ Произведение «<span xmlns:dct="http:// purl.org/dc/terms/" href="http://purl.org/dc/dcmitype/Text" property="dct:title" rel="dct:type">Методика прогноза остаточ- ной нефтенасыщенности и коэффициента вытеснения по данным геофизиче- ских исследований для оценки эффективности применения нанотехнологий $</$ span $>$ » созданное автором по имени $<$ a xmlns:cc $=$ "http://creativecommons.org/ ns\#" href="Нанотехнологии в строительстве. - 2017. - Том 9, № 5. - С. 116-133. - DOI: dx.doi.org/10.15828/2075-85452017-9-5-116-133." property="cc:attributionName" rel="cc:attributionURL"> Ахметов P.Т., Андреев А.В., Мухаметшин В.В. $</ a>$, публикуется на условиях <a rel="license" href="http://creativecommons.org/licenses/by/4.0/">лицензии Creative Commons "Attribution» ( «Атрибуция») 4.0 Всемирная $</ \mathrm{a}>$. $<\mathrm{br} />$ Основано на произведении c $<\mathrm{a}$ xmlns:dct="http:// purl.org/dc/terms/" href="http://nanobuild.ru/ru_RU/nanobuild-5-2017/" rel="dct:source">http://nanobuild.ru/ru_RU/ nanobuild-5-2017/</a $>$. $<$ br / Р Разрешения, выходящие за рамки данной лицензии, могут быть доступны на странице $<$ a xmlns:cc="http://creativecommons.org/ns\#" href="vsh@of.ugntu.ru" rel="cc:morePermissions" >vsh@of.ugntu.ru</a $>$.

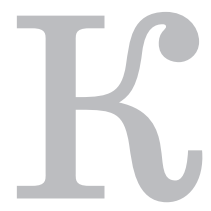

оэффициент вытеснения нефти водой из продуктивных пластов является основным показателем, характеризующим эффективность разработки месторождений путем поддержания пластового давления методом заводнения [1-5].

Знание данного параметра необходимо при подсчете извлекаемых запасов, а также при составлении технологической схемы и проекта разработки месторождений [6-8].

Кроме того, коэффициент вытеснения является важной информацией при оценке динамики добычи нефти [9] и перспектив применения 
методов увеличения нефтеотдачи, в том числе с использованием нанотехнологий [10-13].

До настоящего времени традиционным способом оценки среднего значения коэффициента вытеснения является использование экспериментальных связей между коэффициентом вытеснения и проницаемостью продуктивного пласта. Однако многие исследователи отмечают, что коэффициент вытеснения нефти водой определяется не только фильтрационными свойствами коллекторов, но и характером и степенью смачиваемости поверхности фильтрационных каналов, величиной начальной нефтенасыщенности и т.д.

Хотя коэффициент вытеснения является важным параметром при разработке нефтяных месторождений, до настоящего времени отсутствуют надежные промысловые методы прогнозирования данного параметра непосредственно в скважине, в условиях естественного залегания, что обуславливает отсутствие его учета при оценке эффективности воздействия на призабойную зону пласта [14-19]. В силу этого необходима разработка методики прогноза коэффициента вытеснения по данным промысловой геофизики, позволяющей оценить данный параметр в каждом пластопересечении как по разрезу, так и по площади месторождения. Информация о коэффициенте вытеснения нефти водой позволяет более обоснованно подойти к проблеме локализации остаточных запасов нефти при выборе методов повышения нефтеотдачи.

На современном этапе развития промысловой геофизики по данным ГИС количественно определяются лишь коэффициенты пористости и остаточной водонасыщенности продуктивных пластов, а проблема независимого определения проницаемости даже наиболее простых межгранулярных коллекторов пока остается нерешенной.

Наши исследования указывают на наличие достаточно тесной корреляционной связи между коэффициентом проницаемости и соотношением $K_{\Pi} / K_{B O}$, где $K_{\Pi}-$ коэффициент пористости; $K_{B O}-$ коэфффициент остаточной водонасыщенности [20-23].

Корреляционные связи между указанными параметрами для разных типов коллекторов различные и определяются степенью их гидрофильности. При этом наблюдается отчетливая связь проницаемости от средней толщины пленки связанной воды на поверхности поровых каналов. 
Учитывая то обстоятельство, что зависимости получены не просто статически, а путем математического моделирования структуры пустотного пространства [21], можно с уверенностью утверждать, что они носят универсальный характер и для различных коллекторов отличаются лишь коэффициентами.

$$
K_{\Pi P}=f\left(K_{\Pi} / K_{B O}\right),
$$

где $K_{\text {ПР }}$ - коэффициент проницаемости.

Отметим, что нами ранее были получены аналогичные зависимости для ряда месторождений Широтного Приобъя, а также для карбонатных коллекторов среднего карбона Арланского месторождения [24]. Все эти зависимости имеют общий вид:

$$
K_{\Pi P}=A\left(K_{\Pi} / K_{B O}\right)^{\omega},
$$

где $A$ и $\omega$ - параметры, постоянные для коллекторов определенного класса.

В данной формуле коэффициент $A$ определяется средней толщиной пленки связанной воды, т.е. степенью гидрофильности (гидрофобности) коллектора, а что касается показателя степени $\omega$, то он зависит в основном от степени сцементированности коллектора.

В дальнейшем соотношение $\left(K_{\Pi} K_{B O}\right)$ назовем параметром проницаемости и обозначим $P_{p m}$.

Исходя из вышеизложенного, при построении корреляционных связей для коэффициента вытеснения нефти водой является вполне естественным и логичным использование вместо коэффициента проницаемости параметра проницаемости $P_{p m}$.

При этом для количественной оценки коэффициента вытеснения нефти водой из продуктивных пластов необходимо петрофизическое обоснование корреляционных связей между коэффициентом вытеснения и параметром проницаемости. Как было указано выше, параметр проницаемости характеризует абсолютную проницаемость коллектора.

В связи с разнообразием гранулометрического состава, структуры пустотного пространства и степени гидрофильности терригенных коллекторов корреляционные связи между коэффициентом остаточной нефтенасыщенности и параметром проницаемости для разных пластов 
отличаются, поэтому необходима предварительная адаптация зависимости к условиям конкретного продуктивного горизонта.

Известно, что на стадиях подсчета запасов и проектирования разработки каждого месторождения производятся лабораторные определения коэффициентов остаточной нефтенасыщенности и вытеснения нефти водой на образцах керна, отобранного из продуктивного горизонта. На этих же образцах, как правило, определяются значения коэффициентов пористости и остаточной нефтенасыщенности.

На основании результатов исследований коэффициента остаточной нефтенасыщенности и коллекторских свойств продуктивного горизонта строится график сопоставления

$$
K_{H O}=f\left(P_{p m}\right)
$$

где $K_{\text {но }}$ - коэффициент нефтенасыщенности.

На рис. 1 представлено сопоставление коэффициента остаточной нефтенасыщенности с параметром проницаемости для тульского и бобриковского горизонтов Буряковского месторождения Республики Татарстан. Между указанными параметрами намечается явная корреляционная связь. Однако, как следует из графика сопоставления, теснота связи недостаточно высокая. Это объясняется наличием в составе тульского и бобриковского горизонтов трех классов коллекторов, отличающихся степенью гидрофильности.

Поэтому желательно рассматривать зависимости коэффициента остаточной нефтенасыщенности от параметра проницаемости для каждого класса коллектора по отдельности.

Отметим, что наличие в составе бобриковского горизонта нескольких классов коллекторов, отличающихся степенью гидрофильности точно так же, резко снижает тесноту связи остаточной нефтенасыщенности от абсолютной проницаемости [25-28].

Таким образом, как и следовало ожидать, поверхностные явления на границе порода-флюид оказывают существенное влияние на коэффициент вытеснения нефти водой [29-31].

По этой причине между указанными параметрами имеем три корреляционные связи и, соответственно, три линии регрессии (отметим, что зависимости коэффициента вытеснения от параметра проницаемости имеют аналогичный характер). 


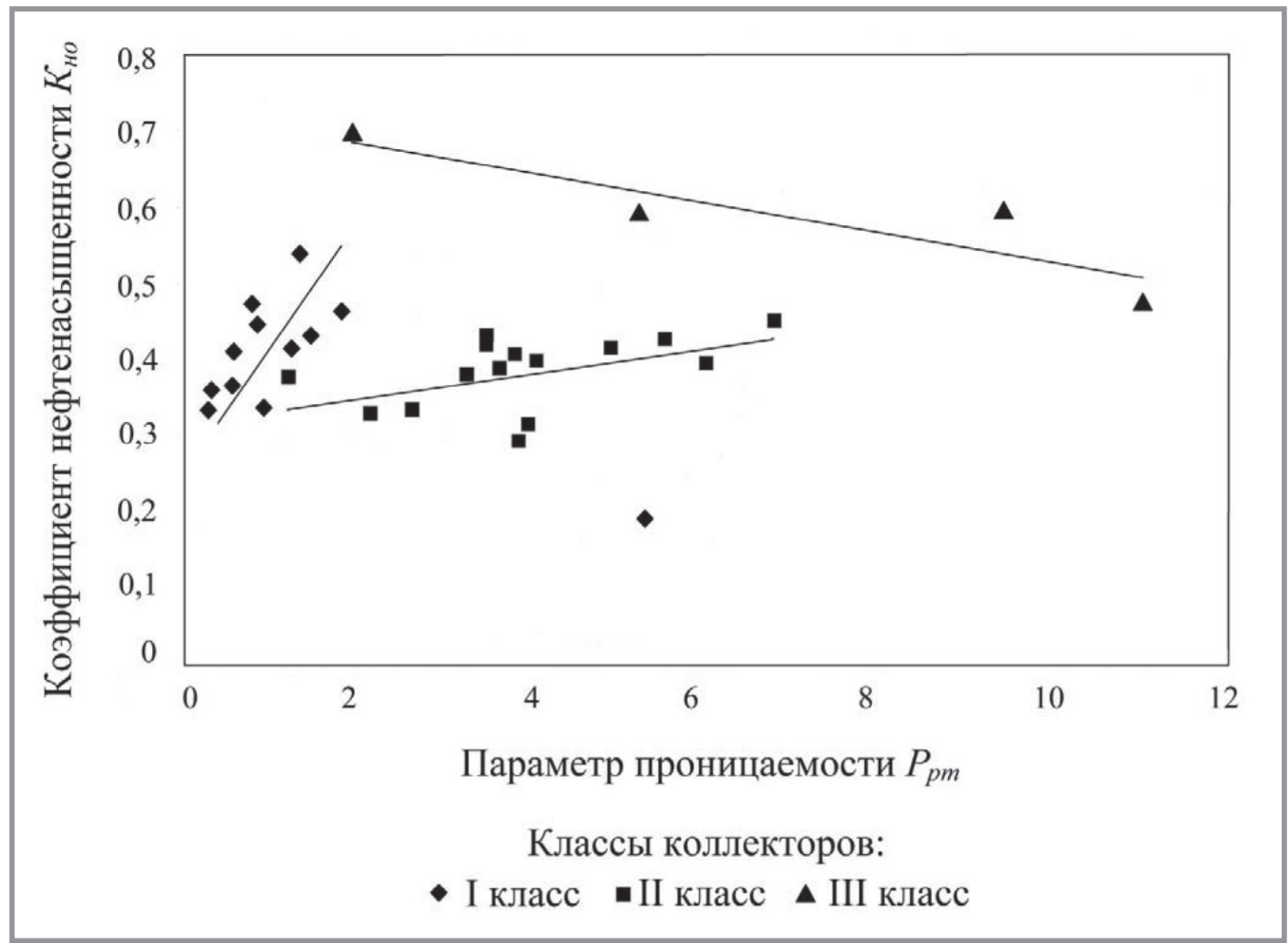

Puc. 1. Зависимость остаточной нефтенасыщенности от параметра проницаемости для тульского и бобриковского горизонтов

Поэтому предварительно должна быть разработана методика, позволяющая разделить коллекторы на три различных класса, отличающихся по степени гидрофильности.

В соответствии с нашими исследованиями существует тесная корреляционная связь между показателем смачиваемости и произведением пористости на коэффициент остаточной нефтенасыщенности [32, 33].

Произведение $\left(K_{\Pi} \cdot K_{B O}\right)$ называется объемной влажностью и обозначается $W_{\text {во }}$. Для гидрофильных коллекторов оно, очевидно, близко к нулю, а для полностью гидрофильных имеет максимальную величину.

На рис. 2 дано сопоставление объемной влажности с коэффициентом пористости образцов керна из тульского и бобриковского горизонтов Буряковского месторождения. 


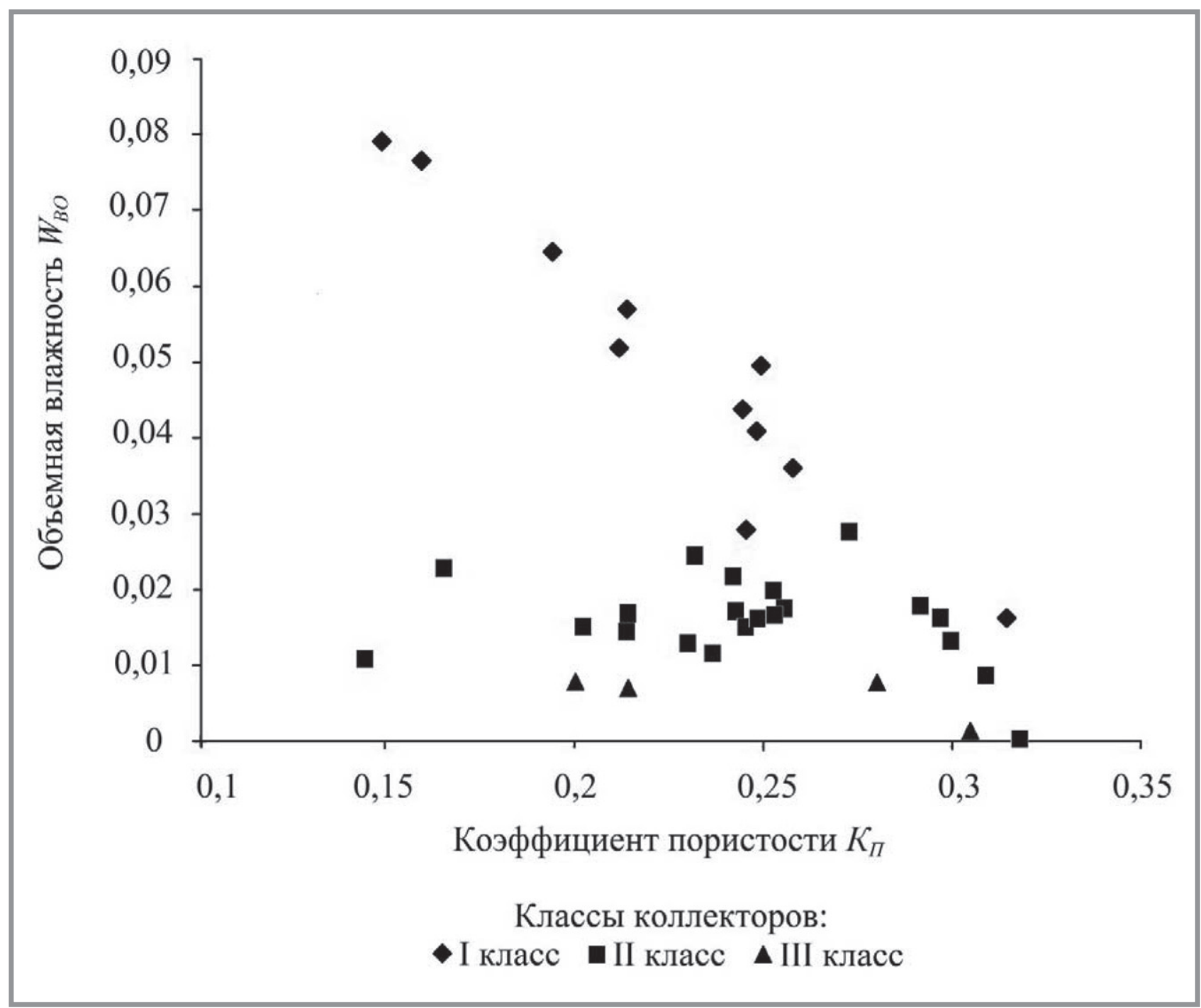

Puc. 2. График зависимости объемной влажности от пористости для тульского и бобриковского горизонтов

Для коллекторов первого класса (соответствующие точки на рис. 2 даны ромбиками) наблюдается тесная связь между объемной влажностью и пористостью, причем с увеличением пористости объемная влажность уменьшается. Вероятно, данная связь осуществляется через глинистость пустотного пространства, причем с увеличением глинистости пористость уменьшается, а остаточная водонасыщенность возрастает.

Коллекторы второго класса (соответствующие точки на рис. 2 даны квадратиками) обладают низкими значениями объемной влажности, не 
зависящими от пористости. Для коллекторов третьего класса объемная влажность минимальная и также зависит от пористости (на рис. 2 эти коллектора отмечены треугольниками).

Таким образом, разделение коллекторов по степени гидрофильности возможно по величине объемной влажности:

I класс $-W_{\text {во }}>0,03$ (гидрофильные коллекторы);

II класс $-W_{B O}=0,01-0,03$ (частично гидрофобные коллекторы);

III класс $-W_{\text {во }}<0,01$ (практически гидрофобные коллекторы).

При этих граничных значениях объемной влажности происходит изменение характера связи между остаточной нефтенасыщенностью и параметром проницаемости.

Отметим, что при высоких значениях пористости $\left(K_{\Pi}>0,27\right)$ степень различия между коллекторами нивелируется.

Учитывая вышеизложенное, нами предлагается следующая схема количественной оценки коэффициента вытеснения нефти водой по данным геофизических исследований скважин (ГИС).

По данным геофизических исследований скважин определяются пористость и остаточная водонасыщенность продуктивного пласта или прослоя. При этом для определения пористости используются методы самопроизвольной поляризации (ПС) или нейтронного гамма-каротажа (НГК), а остаточная водонасыщенность определяется по величине удельного электрического сопротивления пласта (прослоя).

По величине объемной влажности выясняется класс коллектора по степени гидрофильности. Отметим, что объемная влажность может быть оценена непосредственно по удельному сопротивлению пласта.

По графикам зависимости оценивается коэффициент остаточной нефтенасыщенности. При этом необходимо использовать график, соответствующий данному классу коллектора.

В табл. приводится сопоставление значений коэффициентов вытеснения $K_{\text {выт }}$, полученных расчетным путем по предлагаемой методике с данными лабораторного моделирования для тульского и бобриковского горизонтов Буряковского месторождения. В расчетах использованы значения пористости и остаточной водонасыщенности, полученные в лабораторных условиях.

Анализ данных табл. показывает, что ошибка расчета коэффициента вытеснения, в основном, не превышает сотые доли и лишь в одном случае превышает 0,1 . 
Таблица

Сопоставление расчетных величин коэффициента вытеснения с данными лабораторного моделирования

\begin{tabular}{|c|c|c|c|c|c|c|c|c|}
\hline \multirow[b]{2}{*}{$\begin{array}{l}\text { № } \\
\text { III }\end{array}$} & \multirow[b]{2}{*}{$\boldsymbol{K}_{\Pi}$} & \multirow[b]{2}{*}{$\boldsymbol{K}_{B O}$} & \multirow[b]{2}{*}{$W_{\text {во }}$} & \multirow[b]{2}{*}{$\boldsymbol{P}_{p m}$} & \multirow{2}{*}{$\begin{array}{c}\text { Класс } \\
\text { коллек- } \\
\text { тора }\end{array}$} & \multicolumn{2}{|c|}{$\boldsymbol{K}_{\text {выт }}$} & \multirow[b]{2}{*}{$\begin{array}{l}\text { Раз- } \\
\text { ность }\end{array}$} \\
\hline & & & & & & $\begin{array}{c}\text { по лабо- } \\
\text { раторным } \\
\text { данным }\end{array}$ & $\begin{array}{l}\text { по рас- } \\
\text { четным } \\
\text { данным }\end{array}$ & \\
\hline 1 & 0,242 & 0,091 & 0,022 & 2,7 & II & 0,63 & 0,62 & 0,01 \\
\hline 2 & 0,246 & 0,6 & 0,015 & 4,1 & II & 0,58 & 0,59 & $-0,01$ \\
\hline 3 & 0,253 & 0,077 & 0,019 & 3,3 & II & 0,59 & 0,61 & $-0,02$ \\
\hline 4 & 0,237 & 0,048 & 0,012 & 4,9 & II & 0,56 & 0,56 & $-0,00$ \\
\hline 5 & 0,253 & 0,066 & 0,017 & 3,8 & II & 0,57 & 0,59 & $-0,02$ \\
\hline 6 & 0,243 & 0,069 & 0,017 & 3,5 & II & 0,55 & 0,60 & $-0,05$ \\
\hline 7 & 0,254 & 0,069 & 0,017 & 3,7 & II & 0,58 & 0,59 & $-0,01$ \\
\hline 8 & 0,309 & 0,028 & 0,008 & 11 & III & 0,51 & 0,50 & 0,01 \\
\hline 9 & 0,300 & 0,044 & 0,013 & 6,8 & II & 0,53 & 0,52 & 0,01 \\
\hline 10 & 0,295 & 0,053 & 0,016 & 5,6 & II & 0,55 & 0,55 & 0 \\
\hline 11 & 0,314 & 0,052 & 0,016 & 6,0 & II & 0,58 & 0,54 & 0,04 \\
\hline 12 & 0,224 & 0,056 & 0,013 & 4,0 & II & 0,66 & 0,59 & 0,07 \\
\hline 13 & 0,166 & 0,136 & 0,023 & 1,2 & II & 0,56 & 0,56 & 0 \\
\hline 14 & 0,292 & 0,060 & 0,017 & 4,9 & II & 0,42 & 0,56 & $-0,14$ \\
\hline 15 & 0,273 & 0,102 & 0,208 & 2,7 & $\mathrm{I}$ & 0,52 & 0,56 & $-0,04$ \\
\hline 16 & 0,283 & 0,030 & 0,008 & 9,4 & III & 0,39 & 0,45 & $-0,06$ \\
\hline 17 & 0,232 & 0,104 & 0,024 & 2,2 & II & 0,63 & 0,63 & 0 \\
\hline 18 & 0,149 & 0,530 & 0,079 & 0,3 & II & 0,29 & 0,30 & $-0,01$ \\
\hline 19 & 0,249 & 0,064 & 0,016 & 3,9 & II & 0,68 & 0,59 & 0,09 \\
\hline 20 & 0,246 & 0,113 & 0,028 & 2,2 & II & 0,63 & 0,63 & 0 \\
\hline 21 & 0,212 & 0,244 & 0,052 & 0,9 & I & 0,41 & 0,38 & 0,03 \\
\hline 22 & 0,200 & 0,038 & 0,008 & 5,3 & III & 0,38 & 0,35 & 0,03 \\
\hline 23 & 0,249 & 0,408 & 0,100 & 0,61 & $\mathrm{I}$ & 0,39 & 0,34 & 0,05 \\
\hline 24 & 0,248 & 0,166 & 0,041 & 1,5 & I & 0,48 & 0,44 & 0,04 \\
\hline 25 & 0,249 & 0,263 & 0,065 & 0,95 & $\mathrm{I}$ & 0,54 & 0,40 & 0,14 \\
\hline 26 & 0,258 & 0,14 & 0,036 & 1,8 & I & 0,46 & 0,46 & 0 \\
\hline 27 & 0,244 & 0,178 & 0,043 & 1,4 & I & 0,35 & 0,43 & $-0,08$ \\
\hline 28 & 0,25 & 0,197 & 0,049 & 1,3 & I & 0,48 & 0,42 & 0,06 \\
\hline 29 & 0,194 & 0,332 & 0,064 & 0,6 & I & 0,33 & 0,33 & 0 \\
\hline 30 & 0,214 & 0,266 & 0,057 & 0,8 & I & 0,35 & 0,35 & 0 \\
\hline
\end{tabular}


В последние годы в технологиях интенсификации добычи нефти и увеличения нефтеотдачи пластов набирает популярность применение наночастиц. Например, растворы, содержащие наночастицы $\mathrm{SiO}_{2}$ при воздействии на призабойную зону пласта, обладают способностью избирательно блокировать водоносные прослои и одновременно значительно снизить вязкость остаточных углеводородов в смежных прослоях.

При оценке эффективности методов повышения нефтеотдачи, в том числе с использованием нанотехнологий, можно использовать в качестве базы для сравнения результаты расчета коэффициента вытеснения по предлагаемой методике.

\section{Выводы:}

1. Остаточная нефтенасыщенность и коэффициент вытеснения нефти водой существенно зависят от характера и степени смачиваемости продуктивных пластов.

2. Деление коллекторов на отдельные классы в зависимости от степени смачиваемости позволяет резко повысить достоверность и точность оценки коэффициента вытеснения.

3. Предлагаемый способ расчета остаточной нефтенасыщенности и коэффициента вытеснения можно использовать в качестве базы для сравнения при оценке эффективности методов увеличения нефтеотдачи, в том числе с использованием нанотехнологий.

\section{Библиографический список:}

1. Гудок Н.С. Изучение физических свойств пористых сред. - М.: Недра, 1970. $208 \mathrm{c}$.

2. Тульбович Б.И. Коллекторские свойства и химия поверхности продуктивных пород. - Пермь: Перм. кн. изд-во, 1975. - 194 с.

3. Хайрединов Н.Ш. Повышение эффективности заводнения низкопродуктивных залежей нефти в карбонатных коллекторах / Н.Ш. Хайрединов, А.М. Попов, В.Ш. Мухаметшин // Нефтяное хозяйство. - 1992. - № 9. - С. 18-20.

4. Тульбович Б.И. Петрофизическое обеспечение эффективного извлечения углеводородов. - М.: Недра, 1990. - 186 с. 
5. Тульбович Б.И. Методы изучения пород-коллекторов нефти и газа. - М.: Недpa, 1979. - $199 \mathrm{c}$.

6. Гилатудинов Ш.К. Справочное руководство по проектированию разработки и эксплуатации нефтяных месторождений / Ш.К. Гиматудинов, Ю.П. Борисов, М.Д. Розенберг. - М.: Недра, 1983. - 483 с.

7. Ограничение водопритока в горизонтальных скважинах на месторождениях с трудноизвлекаемыми запасами нефти / Р.P. Кадыров, Р.Х. Низаев, А.Ф. Яртиев, В.В. Мухаметшин // Нефтяное хозяйство. - 2017. - № 5. - С. 44-47.

8. Andreev A.V. Deposit Productivity Forecast in Carbonate Reservoirs with Hard to Recover Reserves / A.V. Andreev, V.Sh. Mukhametshin, Yu.A. Kotenev // SOCAR Proceedings. 2016. № 3. P. 40-45.

9. Мухалетшин В.Ш., Зейглан Ю.В., Андреев А.В. Экспресс-оценка потенциала добывных возможностей залежей для определения эффективности применения нанотехнологий и необходимости стимулирования ввода их в разработку / Н Нанотехнологии в строительстве. - 2017. - Том 9, № 3. - C. 20-34. - DOI: dx.doi.org/10.15828/2075-8545-2017-9-3-20-34.

10. Извлечение нефти из карбонатных коллекторов / М.Л. Сургучев, В.И. Колганов, А.В. Гавура и др. - М.: Недра, 1987. - 230 с.

11. Изучение остаточного нефтенасыщения разрабатываемых пластов / Н.Н. Михайлов, А.В. Джемесюк, Т.Н. Кольчицкая и др. - М.: ВНИИОЭНГ, 1990. - 100 с.

12. The Usage of Principles of System Geological-Technological Forecasting in the Justification of the Recovery Methods / V.V. Mukhametshin, V.E. Andreev, G.S. Dubinsky et al. // SOCAR Proceedings. 2016. № 3. P. 46-51.

13. Геологическое и гидротермодинамическое моделирование месторождений нефти и газа / Р.М. Тер-Саркисов, В.М. Максимов, К.С. Басниев и др. - Ижевск: Институт компьютерных исследований, 2012. - 452 с.

14. Зейглан Ю.В., Мухалетшин В.Ш., Сергеев В.В. и др. Экспериментальное исследование вязкостных свойств эмульсионных систем с содержанием наночастиц $\mathrm{SiO}_{2} / /$ Нанотехнологии в строительстве. - 2017. - Том 9, № 2. - С. 16-38. DOI: dx.doi.org/10.15828/2075-8545-2017-9-2-16-38.

15. Мухалетшин B.В. О необходимости и создании единого комплексного метода геолого-промыслового анализа и обобщения эффективности воздействия на призабойную зону пласта // Нефтяное хозяйство. - 2017. - № 4. - С. 80-84.

16. Снижение рисков принятия низкоэффективных управляющих решений при использовании кислотных составов, предотвращающих эмульсиообразование / В.В. Мухаметшин, В.Е. Андреев, Ю.В. Зейгман и др. // Геология, геофизика и разработка нефтяных и газовых месторождений. - 2017. - № 5. - С. 36-42. 
17. Якупов Р.Ф. Вопросы эффективности разработки низкопродуктивных карбонатных коллекторов на примере турнейского яруса Туймазинского месторождения / Р.Ф. Якупов, В.Ш. Мухаметшин // Нефтяное хозяйство. - 2013. № 12 . - С. 106-110.

18. Особенности выбора составов жидкостей глушения скважин в осложненных условиях эксплуатации скважин / Ю.В. Зейгман, В.Ш. Мухаметшин, А.Р. Хафизов и др. // Нефтяное хозяйство. - 2017. - № 1. - С. 66-69.

19. Мухалетшин В.Ш. Зависимость нефтеизвлечения от плотности сетки скважин при разработке низкопродуктивных карбонатных залежей // Нефтяное хозяйство. - 1989. - № 12. - С. 26-29.

20. Ахлетов P.T. Прогноз абсолютной проницаемости гранулярных коллекторов на основе гантельной модели пустотного пространства / Р.Т. Ахметов, Л.Е. Кнеллер // Каротажник. - 2013. - № 7 (229). - С. 75-88.

21. Ахлетов Р.T. Коэффициент абсолютной проницаемости в рамках гантельной модели / Р.Т. Ахметов, В.Ш. Мухаметшин // Нефтегазовое дело. - 2012. № 1. - С. 341-352.

22. Ахлетов P.T. Интерпретация кривых капиллярного давления при смешанной смачиваемости / Р.Т. Ахметов, В.В. Мухаметшин, А.В. Андреев // Геология, геофизика и разработка нефтяных и газовых месторождений. - 2017. - № 4. C. 40-43.

23. Прогноз показателя смачиваемости продуктивных пластов по объемному содержанию остаточной воды / Р.Т. Ахметов, Ю.В. Зейгман, В.В. Мухаметшин и др. // Известия ВУЗов. Нефть и газ. - 2017. - № 2. - С. 39-43.

24. Ахлетов Р.T. Количественная оценка проницаемости карбонатных коллекторов каширо-подольских отложений Арланского месторождения по данным ГИС / Сборник научных трудов БашНИПИнефть. - Уфа. - 1995. - Вып. 91.

25. Злобин A.A. Влияние смачиваемости пород-коллекторов на коэффициент извлечения нефти // Нефтепромысловое дело. - 2013. - № 9.- С. 49-53.

26. Михайлов А.Н. Влияние капиллярных концевых эффектов на показатели разработки // Нефтяное хозяйство. - 2013. - № 9 - С. 54-56.

27. Михайлов Н.Н. Влияние микроструктурной смачиваемости на петрофизические характеристики пород-коллекторов / Н.Н. Михайлов, Н.А. Семенова, Л.С. Сечина // Каротажник. - 2011. - № 7. - С. 163-172.

28. Влияние смачиваемости на коэффициент вытеснения нефти / Г.П. Хижняк, А.М. Амиров, А.М. Мошева и др. // Вестник Пермского национального исследовательского политехнического университета. Геология. Нефтегазовое и горное дело. - 2013. - Том 12, № 6. - С. 54-63. 
29. Михайлов А.Н. Теоретические и экспериментальные исследования особенностей вытеснения нефти водой из пластов с контрастной смачиваемостью / А.Н. Михайлов, С.В. Мелехин // Вестник ЦКР Роснедра. - 2014. - № 1. C. $12-18$.

30. Михайлов Н.Н. Геологические факторы смачиваемости пород-коллекторов нефти и газа / Н.Н. Михайлов, К.А. Моторова, Л.С. Сечина / Деловой журнал Neftegaz.RU. - 2016. - № 3. - C. 80-90.

31. Михайлов Н.Н. Влияние состава углеводородов на гидрофобизацию карбонатных пород / Н.Н. Михайлов, К.А. Моторова, Л.С. Сечина // Тезисы докладов $\mathrm{V}$ Международного научного симпозиума «Теория и практика применения методов увеличения нефтеотдачи пластов». - 2015. - С. 29-36.

32. Ахлетов Р.Т. Прогноз показателя смачиваемости продуктивных пластов по данным промысловой геофизики / Р.Т. Ахметов, В.Ш. Мухаметшин, В.Е. Андреев // Геология, геофизика и разработка нефтяных и газовых месторождений. - 2016. - № 2. - С. 21-25.

33. Ахлетов Р.T. Водоудерживающая способность и смачиваемость продуктивных пластов / Р.Т. Ахметов, В.В. Мухаметшин // Нефтегазовое дело. - 2016. Toм 14, № 2. - C. 34-37.

\section{УВАЖАЕМЫЕ КОЛЛЕГИ!}

ПРИ ИСПОЛЬЗОВАНИИ МАТЕРИАЛА ДАННОЙ СТАТЬИ

ПРОСИМ ДЕЛАТЬ БИБЛИОГРАФИЧЕСКУЮ ССЫЛКУ НА НЕЁ:

Ахметов Р.T., Андреев А.В., Мухалетшин В.В. Методика прогноза остаточной нефтенасыщенности и коэффициента вытеснения по данным геофизических исследований для оценки эффективности применения нанотехнологий // Нанотехнологии в строительстве. - 2017. - Том 9, № 5. - C. 116-133. - DOI: dx.doi.org/10.15828/2075-8545-2017-9-5-116-133.

\section{DeAR COLlEagues!}

THE REFERENCE TO THIS PAPER HAS THE FOLLOWING CITATION FORMAT:

Akhmetov R.T., Andreev A.V., Mukhametshin V.V. Residual oil saturation and the displacement factor prediction methodology based on geophysical studies data to evaluate efficiency of nanotechnologies application. Nanotehnologii v stroitel'stve $=$ Nanotechnologies in Construction. 2017, Vol. 9, no. 5, pp. 116133. DOI: dx.doi.org/10.15828/2075-8545-2017-9-5-116-133. (In Russian). 